\title{
XXXIII. Observations on the effects of age upon fruit trees of different kinds; with an account of some new varieties of nectarines. In a letter to the secretary
}

\section{Thomas Andrew Knight Esq. F.R.S.}

To cite this article: Thomas Andrew Knight Esq. F.R.S. (1824) XXXIII. Observations on the effects of age upon fruit trees of different kinds; with an account of some new varieties of nectarines. In a letter to the secretary , Philosophical Magazine Series 1, 64:317, 194-197, DOI: 10.1080/14786442408644584

To link to this article: http://dx.doi.org/10.1080/14786442408644584

$$
\text { 曲 Published online: } 27 \text { Jul } 2009 .
$$

Submit your article to this journal $₫$

\section{山 Article views: 2}

Q View related articles ¿ 
XXXIII. Observations on the Effects of Age upon Frit Trees of different Kinds; with an Account of some new Varieties of Nectarines. In a Letter to the Secretary. By Thomas Andrew Knight, Esq. F.R.S. \&c. President.*

\section{My dear Sir,}

WANY new varieties of fruits of different species having 1 been sent from my garden to the Horticultural Society in the last and in preceding seasons, and some others having been seen by you in the short visit which I had the pleasure to receive from you in the last autumn, I feel desirous to offer a few observations upon the expediency of obtaining such productions; or rather, upon the question, whether each variety have its period of youth, of maturity, and of old age, and be formed for a limited period of duration only; or whether each be capable of eternal propagation, with undiminished health and vigour.

The fact, that certain varieties of some species of fruits which have been long cultivated, cannot now be made to grow in the same soils, and under the same mode of management, which was a century ago perfectly successful, is placed beyond the reach of controversy. Every experiment which seemed to afford the slightest prospect of success, was tried by myself and others, to propagate the old varieties of the Apple and Pear, which formerly constituted the orchards of Herefordshire, without a single healthy or efficient tree having been obtained; and, I believe, all attempts to propagate those varieties have, during some years, wholly ceased to be made. I have detailed in the Philosophical Transactionst, an account of some experiments, which I repeated, with the hope of being able to ascertain which, amongst the various organs of trees of aged varieties, first fail to execute their proper func-tions; and 1 came to the conclusion, upon the following and other evidence, that it is the leaf. Having obtained by layers or cuttings, small plants of several of the most diseased of the old varieties of the Apple, these were grafted within a couple of inches of the surface of the soil with scions of new seedling and luxuriant varieties; and under these circumstances the roots of the most debilitated and diseased varieties executed their office perfectly well, and were found, upon examination, at the end of several years, wholly free from every symptom of disease. This process was reversed, and scions of old varieties were employed as grafts; but into the young growing

* From the Transactions of the Horticultural Society, vol. v. Part IV.

+ For the year 1810, page 178 . 
shoots, which sprang from these, many lapds of new and luxuriant varieties were inserted, and in the autumn every natural bud of the old varieties was destroyed. The inserted buds vegetated in the following spring, and by these efficient foliage was given; when every symptom of debility and disease disappeared, and the wood and bark of the most exhausted and diseased varieties now constitute a part of the stems of large apple trees, and present, at the end of thirty years, as much apparent health as other parts of the stems of those trees. From these results I have inferred, that the debility and diseases of such old varieties arise from the want of a properly prepared circulating fluid; and that when such is given by efficient foliage, the bark of the most debilitated variety possesses the power to occasion the necessary secretions to take place, and the alburnum is enabled to execute all its offices.

It has been urged against the conclusion, that old age is the cause of debility and decay of those varieties of fruit which have been very long cultivated, that many of the seedling offspring of such varieties are as much diseased as their parents; and it is contended, that the failure of our best old varieties of fruit has arisen from a succession of unfavourable seasons. The fact, that many of the seedling offspring of old diseased varieties of fruit are as much diseased as the parents from which they spring, is unquestionable; but this, I conceive, proves nothing more than that diseases are hereditary in the vegetable as they are in the animal world; and it is scarcely reasonable to expect that healthy and robust offspring can be obtained from parents, whose lives have been extended beyond their natural periods by preternatural means, and whose bodies are yearly falling to pieces under the operation of disease; and in which the whole of the circulating fluids are in a morbid state.

If a deterioration have taken place in our climate, and this have occasioned the decay of our fruit trees, at what period did this deterioration take place? It is more than forty years since I commenced experiments with the hope of being able to raise healthy trees of the old varieties of the Cider Fruits of Herefordshire; and I know that the progressive debility of those had been pointed out some years before my birth by my father, who died an old man when I was an infant; and who was an extremely competent judge of the subject.

Parkinson also, who lived in the reign of Elizabeth, complains of the unfavourable seasons in the latter part of his life. The grapes did not then ripen as they had formerly done; or more probably, I believe, he did not find them so sweet as he $\mathrm{B}$ b 2 though $_{t}$ 
thought them when he was a school-boy. That some change may, however, have taken place in our climate, owing to the operation of many concurrent causes, is not improbable, but not in a degree equivalent to the effects produced. Any considerable change of climate must also have affected alike the new and the old varieties of fruits, and the decay of the latter alone seems therefore to prove some constitutional change to have taken place in those.

If the leaf gradually fail to execute properly its office, a progressive degree of debility, preceding a state of disease and decay, must necessarily follow; and this I have noticed in some moderately old varieties of the Apple and Pear. They remain free from disease; they blossom frequently, and sometimes freely; but they rarely afford much fruit; and their recovery, from the exhausted state in which even a moderate crop of fruit leaves them, is very slow. If this state be induced, as I am well satisfied that it is, by the inefficient operation of the foliage, it becomes an interesting question at what period of the age of each variety such defective operation commences. The observations which I have had opportunities of making, lead me to believe that it commences at the period when the original tree becomes, according to the ordinary course of nature, debilitated by age; and I suspect that much the greater part of the varieties of fruit, of different species, which are now named in the catalogues of nurserymen, have already outlived the periods at which they best deserved the attention of the planter. This remark I wish particularly to apply to the Peach and Nectarine; varieties of which, of equal excellence and much superior vigour and hardiness, may be easily obtained from seeds ripened in the forcing-houses, if not upon the open walls, of our gardens. I sent to you, in the last autumn, many new varieties of Nectarines raised in my Peach-house from seeds of the Elruge and the pollen of the Early Violet Nectarine. They were the produce of buds inserted into the bearing branches of old Peach and Nectarine trees growing upon my walls, the original seedling trees not having been retained in my garden.

Every attention was paid to make the fruit from which the seeds were taken attain the highest state of perfection, and the crop of fruit of the trees which bore them, and from which the pollen was taken, was sacrificed almost wholly in the preceding season, that both those might be in the most efficient and vigorous state; and 1 preferred the forcing-house to the open wall, that the wood and blossoms might attain the most perfect state of maturity. Of the merits of the Nectarines you received, I wish to decline giving an opinion; and I shall 
Mr. Herapath on the Solution of Functional Equations. 197

therefore only remark, that in every unfavourable season, such as the last, the stones are always found larger, relatively to the bulk of the fruit, than in favourable seasons. But of the habits of the trees, or rather of the branches, (for few of the trees have been preserved,) I can speak with much satisfaction. The wood of many has ripened more perfectly, and offers a much stronger and more abundant blossom than is found on any of the branches of the parent varieties: and I feel perfectly confident that some of the new varieties, and particularly one of them, will succeed in forming blossoms, and ripening fruit in seasons and situations too cold for either of the old varieties from which they sprang.

Buds of any of the varieties, which you may think deserving culture, shall be sent in the proper season. Having preserved and given a place to the original tree upon my wall of one (which I believe you agreed with me in thinking the best, and to which you proposed to give the name of the Downton Nectarine) I shall be able to supply a much larger number of buds of that, than can be wanted.

I remain, my dear sir, sincerely yours,

Downton, Feb. 28, 1824.

Thomas Andrew Knigh'r.

Note by the Secretary.

April 17, 1824.-Mr. William Christie, the Fruit and Kitchen Gardener of the Society, having been at Downton during part of the last week, was much struck with the appearance of the blossoms of the new nectarines mentioned by the President in the above paper; they were particularly plump and strong, and their colour very bright and lively, all indicating vigour of constitution in the branches producing them.

XXXIV. On the complete Solution of certain Functional Equations. By John Herapath, Esq.

LET us take the well-known equation

$$
\psi x+f x \cdot \psi \alpha x=f_{i} x
$$

the conditions being $\alpha^{2} x=x, f x . f \alpha x=1$, and $f x . f_{1} \alpha x=f_{1} x$. Substituting $v \psi x+b \phi x$ for $\psi x$ wherein $v=1$, and $b=0, \phi x$ being any arbitrary function, we have

$$
v \psi x+b \varphi x+\frac{\psi \alpha x}{f \alpha x}=f_{i} x .
$$

Then changing $x$ into $a x$, our conditions give

$$
v f \cdot . \psi \alpha x+b f x \cdot p \alpha x+\psi x=f_{1} \alpha x \cdot f x=f_{1} x
$$

